\title{
A EDUCAÇÃO À DISTÂNCIA NO PROCESSO DE TRANŞPOSIÇÃO DE PRAXEOLOGIAS DIDÁTICAS
}

\author{
Iza Helena Silva TRAVASSOS ${ }^{1}$ \\ Instituto de Ciências da Educação/UFPA \\ izahelena@ufpa.br \\ Renato Borges GUERRA ${ }^{2}$ \\ Programa de Pós-graduação em Ciências e Matemática/UFPA \\ rguerra@ufpa.br
}

Resumo: Este artigo trata das praxeologias dos sujeitos - professores em formação e formadores - que vivenciaram o processo de formação de professores de Matemática na modalidade de ensino à distância. O aporte teórico adotado para as análises foi a Teoria Antropológica do Didático e a metodologia de investigação utilizada foi do tipo qualitativa com uma abordagem etnográfica. Os resultados obtidos apontam para uma transposição de praxeologias do ensino a distância para o ensino presencial.

Palavras-chave: Formação de Professores. Educação à Distância. Teoria Antropológica do Didático.

Abstract: This paper deals with the praxeologies of the subjects - professors in formation and educators - that they had lived deeply the process of formation of professors of Mathematics in the distance education modality. The theoretical support adopted for the analyses was the Anthropological Theory of the Didactic and the methodology of investigation used was of the qualitative type with an ethnographic boarding. The gotten results point to a transposition of praxeologies in the distance education for actual education.

Keywords: Formation of Professors. Distance Education. Anthropological Theory of the Didactic.

\footnotetext{
${ }^{1}$ Licenciada Plena em Matemática pela Universidade Federal do Pará (UFPA); Mestre pelo Programa de Pós-Graduação em Educação em Ciências e Matemáticas da UFPA; Professora Assistente I lotada no Instituto de Educação da UFPA.

${ }^{2}$ Licenciado Pleno em Matemática (UFPA); Mestre em Matemática Aplicada (UNICAMP); Doutor em Engenharia Elétrica (UNICAMP); Professor Adjunto do Programa de Pós-Graduação em Educação em Ciências e Matemáticas da UFPA.
} 


\section{Considerações iniciais}

Esta pesquisa foi desenvolvida dentro de um processo ainda em construção: a implantação do curso de Licenciatura em Matemática na modalidade à distância da Universidade Federal do Pará (UFPA). O nosso contexto é o de formação de professores de Matemática em exercício na modalidade à distância. Tomamos como desafio investigar as possíveis mudanças na prática docente dos professores em formação, a partir da experiência discente no curso, e nos coordenadores de disciplina e tutores do curso, a partir da experiência docente.

Esse contexto apresenta diversas peculiaridades, dentre elas as que mais se destacam são referentes à modalidade de ensino à distância, por todas as questões relativas às resistências e desconfianças para com a EAD, pois, em nosso País, ainda existe um imaginário negativo quanto a esta forma educativa (ALONSO, 2000). Outro leque de questões que surge dentro desse contexto está relacionado a como se dá o processo de ensino nessa forma de se fazer educação.

Quando tratamos da EAD, geralmente, suscitamse discussões em torno de como se realiza um processo educativo onde as figuras tradicionais, como sala de aula, professores e alunos, não estão materializadas nos modelos que conhecemos, e quando alunos e professores não estão realizando seus papéis educativos em um mesmo espaço e tempo (ALONSO, 2000, p. 231).

Alonso (2000) afirma, ainda, que na EAD essas figuras continuam a existir, mas com características e funções diferentes das que conhecemos no ensino presencial. A obtenção de independência e da autonomia por parte dos alunos em relação ao professor pode assustar a maioria dos professores, pois os faz temer pela continuidade de boa parte de seu "poder". No curso da UFPA, as nossas inquietações estão imbricadas no processo desencadeado pela EAD e experienciado pelos professores em formação e formadores - coordenadores de disciplina e tutores - nos processos de ensinar e aprender vivenciados por eles.

A EAD pressupõe o aluno como responsável pelo seu aprendizado, embora sua prática não se reduza exclusivamente ao aluno. Os meios pelos quais isso se desenvolverá e o atendimento por um tutor, cuja função é 
orientar o aluno e esclarecer dúvidas relativas ao estudo da disciplina pela qual é responsável, são essenciais para o processo educacional (BARROS, 2003). Mas será que essa valorização da autonomia do aluno e a visão do professor como orientador de estudos refletem, de alguma forma, na prática deles? Será que o curso de Matemática da UFPA proveria, na sua formação, professores preocupados com o processo de estudo, com o desenvolvimento da autonomia dos alunos e outras características próprias a serem desenvolvidas por alunos de cursos na EAD?

Essas questões surgiram não somente a partir de nossa experiência em tutorias e planejamento de disciplinas dentro do curso de Matemática, elas tomaram corpo quando, em conversas informais com os formadores, nós percebíamos que eles apresentavam um novo olhar sobre o ensino presencial a partir de suas experiências na modalidade à distância. $\mathrm{O}$ conteúdo das conversas informais foi identificado também nas entrevistas com esses formadores, que afirmaram que sua experiência dentro de um curso, na modalidade à distância, estava influenciando diretamente a sua concepção de prática docente e comportamento em sala de aula no ensino presencial.

Para respondermos algumas de nossas questões, escolhemos como aporte teórico a Teoria Antropológica do Didático (TAD), do educador matemático francês Yves Chevallard, por entendermos que elementos dessa teoria apresentam congruências com os pressupostos da EAD, e utilizamos como metodologia de investigação, a investigação qualitativa.

A escolha pela investigação qualitativa se deu porque tínhamos um contato direto com a situação estudada e os sujeitos investigados; nós estávamos inseridos no contexto do curso, fazendo parte da dinâmica das disciplinas em seus planejamentos e tutorias; os dados eram descritivos e buscávamos retratar as perspectivas dos participantes da pesquisa (BOGDAN; BIKLEN, 1994).

Além disso, identificamos que atuávamos sob os critérios utilizados na abordagem etnográfica, uma vez que o nosso problema de pesquisa foi redescoberto em campo; nós realizamos a maior parte do trabalho de campo pessoalmente; o nosso trabalho de campo durou dois semestres letivos; combinamos vários métodos de coleta e os nossos dados são basicamente primários (WILSON, 1997, apud LÜDKE; ANDRÉ, 1986). 
Os sujeitos pesquisados foram cinco professores em formação, do pólo de Breves, que atuavam como docentes de turmas de quinta à oitava série, na escola "Julião Bertolo de Castro", no município de Bagre, localizado na Ilha do Marajó - Pará, e dois professores, doutores em Matemática que são docentes da UFPA e que atuaram como formadores no curso, ou seja, como tutores ou coordenadores de disciplina.

Os dados utilizados foram: materiais didáticos das disciplinas, relatórios de tutorias presenciais, observação das aulas dos professores em formação, diários de bordo e entrevistas semiestruturadas com professores formadores e professores em formação.

\section{A educação à distância como força propulsora do processo} de transposição

\subsection{Sobre os processos de transposição}

A noção de transposição didática proposta por Chevallard (2005) está relacionada às transformações do saber, de sua origem até a chegada nas escolas, ou seja, nos processos de adaptação deste saber. Por outro lado, nós temos uma relação que o professor estabelece com este saber. Quando nos referimos à relação entre professor e saber, nos referimos à epistemologia do professor. Sobre a epistemologia do professor, Pais nos diz que:

[...] entendemos a epistemologia do professor como sendo as concepções referentes à disciplina com que trabalha esse professor, oriundas do plano estrito de sua compreensão e que conduzem uma parte essencial de sua postura pedagógica, em relação ao entendimento dos conceitos ensinados aos alunos. [...] Quando se analisa a epistemologia do professor surgem crenças enrijecidas pelo tempo, que podem gerar uma visão puramente pessoal sobre a ciência ensinada (2001, p. 34, grifos nossos).

As concepções do professor sobre o saber, que por sua vez está condicionado à sua compreensão, orientam uma parte de suas práticas adotadas em sala de aula. Nesse sentido, a relação entre professor e saber influencia diretamente em sua prática por que: 
A utilidade do saber permite ao sujeito um referencial de análise capaz de the proporcionar um olhar mais amplo e indagador. É exatamente essa possibilidade de transformação que permite uma espécie de transposição interna do saber sobre o seu próprio campo epistemológico. Em suma, quando o sujeito passa a ter um relativo domínio sobre um determinado saber, torna-se possível desencadear uma práxis transformadora e também geradora de novos saberes (PAIS, 2002, p. 15-16).

Mas o desencadeamento de uma nova práxis não se dá somente a partir de uma nova relação do sujeito com o saber, uma vez que o sujeito, dentro de uma instituição, estabelece uma relação com novas praxeologias. As praxeologias são produzidas ou reproduzidas dentro das instituições, mais especificamente das instituições didáticas. Assim como o saber, que sofre transformações que começam na noosfera, as praxeologias passam por mudanças adaptativas quando "importadas" de uma instituição para outra. O trabalho de transformação de um saber acadêmico em um saber ensinado é uma transposição didática, enquanto que o trabalho de adaptação, modificação e transformação de uma praxeologia é uma transposição de praxeologia.

Los procesos de transposición institucional exceden sin ninguna duda la transposición didáctica propiamente dicha; pero ya indiqué hasta qué punto toda transposición institucional tiende actualmente a articularse en una transposición didáctica, que es uno de sus momentos cruciales. Los procesos transpositivos - didácticos y más generalmente institucionales - son, tal como se imagina, el resorte esencial de la vida de los saberes, de su diseminación y su funcionalidad adecuadas (CHEVALLARD, 1999, p. 158-159).

A construção de uma praxeologia está intrinsecamente ligada a um determinado saber, portanto, a transposição didática e a transposição de praxeologias fazem parte de um mesmo processo, pois novos saberes geram novas praxeologias, assim como novas praxeologias geram novos saberes.

Quando Chevallard (1999) se refere à transposição de praxeologias, ele afirma que este processo ocorre de uma instituição para outra, 
denominando-o como um processo de transposição institucional. Porém, em nossas análises, nós percebemos que o trabalho de adaptação de uma praxeologia não ocorre somente de uma instituição para outra; esse trabalho, ou melhor, essa transposição de praxeologias pode ocorrer dentro de uma mesma instituição, como veremos no decorrer deste capítulo.

Os cinco sujeitos de nossa pesquisa, que são os professores em formação, exercem sua prática docente em turmas do ensino presencial e são discentes do curso de Matemática na modalidade à distância da UFPA. Os outros dois sujeitos são formadores no referido curso da UFPA, mas foram "formados" e atuam em cursos na modalidade de ensino presencial dessa mesma instituição. A referida escola é uma escola municipal de ensino fundamental que oferece um ensino presencial seriado, e a UFPA é uma instituição de ensino superior que oferece cursos de graduação em Licenciatura em Matemática nas modalidades de ensino presencial e à distância.

Durante o processo de formação de professores de matemática na modalidade à distância da UFPA, esses sujeitos - professores em formação e formadores - tiveram a oportunidade de estabelecer uma nova relação com o saber - escolar e acadêmico - que é ensinado em suas salas de aula do ensino presencial. Mas, além disso, o curso da UFPA propiciou uma relação com um novo tipo de praxeologias, uma vez que a modalidade de ensino é a educação à distância, na qual professor e aluno desempenham papéis diferentes dos quais realizam no ensino presencial.

No curso, nós vivenciamos o papel de formador, uma vez que éramos tutores das disciplinas "Instrumentação do Ensino de Matemática" (IEM) e "Estágio Supervisionado II". Além disso, trabalhávamos no planejamento das referidas disciplinas juntamente com o coordenador delas, o que nos oportunizou ter contato com os professores em formação e com os formadores.

O contato com os professores em formação se dava durante as tutorias presenciais realizadas nos finais de semana e o contato com os formadores era feito por meio de reuniões do curso e conversas informais na UFPA. Durante as reuniões e conversas, nós identificamos nesses formadores uma mudança de concepções acerca do ensino presencial a partir de suas experiências no curso na modalidade à distância. Essa 
mudança era compartilhada por nós, uma vez que estávamos inseridos no processo.

\subsection{Transposição de Praxeologias Didáticas}

Nós identificamos, em nossas análises, uma transposição de tarefas, técnicas e tecnologias mobilizadas para o estudo da matemática, ou seja, uma transposição de praxeologias didáticas. Essas praxeologias didáticas, de forma análoga às praxeologias matemáticas, sofrem um conjunto de mudanças adaptativas para tomarem lugar em uma determinada instituição. Porém, devemos considerar que:

El profesor no elige arbitrariamente las técnicas didácticas que utiliza sino que, por el contrario, esta elección está ligada a una manera más o menos explícita a ciertos argumentos justificativos e interpretativos de dichas técnicas. Estos argumentos abarcan también los presuntos beneficios didácticos de la utilización de una $u$ otra técnica $y$ dependen de la institución donde tiene lugar la enseñanza, de la formación que ha recibido el profesor, de sus conocimientos $y$ creencias $y$, en definitiva, de sus múltiples sujeciones a diferentes instituciones (escolares, científicas, culturales) (BOSCH; GASCÓN, 2001, p. 2 - grifo nosso).

Nesse sentido, percebemos que o processo de formação de professores influenciou diretamente na produção ou reprodução de organizações didáticas voltadas para o estudo de um saber matemático. Além disso, a experiência do professor em uma determinada instituição, à qual ele se sujeita, pode implicar na (re)formulação das suas organizações didáticas. Em nossas análises, nós percebemos que a modalidade de ensino na qual o professor vivencia sua formação ou atua como formador implica na escolha/construção de praxeologias didáticas a serem adotadas em sua sala de aula.

Ambos os formadores afirmaram que a experiência em EAD trouxe contribuições para sua prática docente, ou seja, propiciou a (re)construção de praxeologias didáticas. Mas as práticas institucionalizadas da EAD não foram apenas adotadas de forma integral no ensino presencial, eles as 
adaptaram à sua realidade, ou seja, as mudanças de práticas dos formadores se deram através de um processo de adaptações de praxeologias didáticas adotadas na EAD, dentre as quais, nós podemos destacar: a formação das comunidades de estudo para o estabelecimento do processo de estudo por meio de uma relação com a obra matemática. Nesse sentido, temos uma transposição de praxeologias de uma modalidade de ensino à distância para uma modalidade de ensino presencial, dentro de uma mesma instituição.

Nós percebemos, ainda, que os formadores, a partir da experiência no curso de Matemática, apresentaram uma preocupação com o processo de estudo por meio de obra matemática e com a responsabilidade matemática. Em suas entrevistas, o verbo "estudar" surgiu como algo importante dentro do processo de ensino e aprendizagem, quando eles afirmam que:

Não adianta o aluno ficar quatro ou cinco horas assistindo aula por dia e não ler nada em casa, como eu falei ainda agora, para você ficar só assistindo aula, você não está construindo conhecimento nenhum seu, não adianta, você tem que sentar e estudar (FORMADOR A, entrevista grifo nosso).

A contribuição principal é no sentido de que o aluno é obrigado a ler, porque professor só vai uma vez de quinze em quinze dias, então o aluno é obrigado a saber estudar (FORMADOR B, entrevista - grifos nossos).

Percebemos que o Formador A vê o processo de estudo como indispensável quando afirma que não adianta apenas ensinar, pois, para que o aluno aprenda, ele tem que estudar. O Formador B já nos apresenta algo peculiar ao curso na modalidade à distância: o fato de que $\mathrm{o}$ estudante é obrigado a ler, ou seja, ele deve entrar em contato com a obra matemática e estudar esta obra.

Chevallard et al. (2001), dentro de sua teoria, utiliza o termo "processo didático". Para ele, o processo de ensino e aprendizagem é uma parte do processo didático, o ensino é englobado pelo processo de estudo, o ensino é um meio para o estudo: 
O didático é tudo aquilo que se refere ao estudo. Falaremos de processos didáticos toda vez que alguém se veja levado a estudar algo - no nosso caso será a matemática - sozinho ou com a ajuda de outra(s) pessoa(s). A aprendizagem é o efeito buscado pelo estudo. O ensino é um meio para o estudo, mas não é o único (CHEVALLARD et al., 2001, p. 58).

Entretanto, os formadores não foram os únicos a sereminfluenciados pelas práticas adotadas no curso de Matemática na modalidade à distância da UFPA. Os professores em formação, que vivenciaram estas práticas como alunos do curso, sofreram estas influências em seu processo de formação.

A obra matemática era o livro-texto da disciplina "IEM", o qual eles deveriam estudar as aulas indicadas no planejamento semanalmente. Esses professores eram "obrigados" a entrar em um processo de estudo, no qual eles (re)construíam praxeologias matemáticas propostas pelo livro-texto. Para desenvolver as atividades propostas pelo livro-texto de "IEM" e pela disciplina "Estágio II", eles formavam grupos, porém existia um grupo maior que era formado por todos os alunos da turma e pela tutora. Este grupo formava uma comunidade de estudos, uma vez que seus membros compartilhavam expectativas e experiências, bem como as dúvidas, e as vitórias e insucessos.

Nós fazíamos parte dessa comunidade no papel de coordenador de estudos, nos encontros presenciais nós orientávamos o processo de estudo na comunidade de tal forma que houvesse uma crescente responsabilidade matemática dos alunos. Percebemos uma ampliação da nossa responsabilidade matemática, uma vez que também estávamos estabelecendo uma nova relação com os saberes e uma relação com novos saberes.

Mas a formação de comunidades de estudo e o processo de estudo de uma obra matemática não são ações isoladas que ocorreram somente nas disciplinas "IEM" e "Estágio II". Estas são ações institucionalizadas em todas as disciplinas do curso de Licenciatura em Matemática na modalidade à distância. Dentre estas ações, o processo de estudo de uma obra matemática é destacado pelos formadores.

Diante deste contexto, identificamos que as práticas experienciadas pelos professores em formação no curso, não especificamente nas 
disciplinas "IEM" e "Estágio II", se refletem em suas práticas docentes no ensino presencial. Nós percebemos que alguns desses professores se preocupavam com o processo de estudo de uma obra matemática e que procuraram estratégiasque possibilitassem umacrescente responsabilidade matemática de seus alunos.

A professora Tereza, semelhante ao Formador B, se refere ao fato de o aluno ter que saber ler e interpretar, para que ele possa realizar as tarefas:

O tema da minha aula é subtração. Eu já comecei o assunto $e$ hoje nós vamos dar continuidade. As atividades vão ser só os exercícios que eu tenho no meu caderno para passar pra eles. Eu pretendo fazer com que eles assimilem e tenham mais facilidade em resolver, porque os problemas agora são mais contextualizados e eu quero que eles tenham mais facilidade em interpretar e ler. Eu cobro muito a leitura deles, você vai perceber isso, porque se eles não souberem ler e interpretar, eles não vão saber resolver. [...] Eles liam, mas não entendiam o que liam. Então vai ser assim, porque eles vão ter que ler mais, parar um pouco para pensar e raciocinar para poder resolver (TEREZA, primeiro dia de observação - grifo nosso).

Podemos perceber que a professora Tereza enfatiza o processo de leitura de uma obra matemática, uma vez que, para se resolver uma tarefa, é necessário interpretar, pensar e raciocinar sobre a mesma. Já a professora Madalena, em suas entrevistas, levanta explicitamente a questão do estudo. Ao ser perguntada sobre a origem das dificuldades apresentadas por seus alunos em relação ao ensino das expressões algébricas, ela nos disse:

É na verdade um assunto complicado, até porque é muito abstrato pra eles. [...] minha grande confusão com eles é porque na verdade são crianças que nós percebemos que, na verdade, não estudam. Eles deixam pra estudar na aula, na hora da aula. E aí então complica mais um pouco, porque eles não têm o hábito de estudar (MADALENA, entrevista, terceiro dia de observação - grifo nosso).

Além de apontar a falta de hábito de estudar como uma das origens das dificuldades na aprendizagem, ela ainda aponta o que poderia ajudar 
nesse processo. Segundo Madalena, seria fundamental "que eles, por exemplo, tentassem estudar em casa, refizessem os exercícios, vissem o assunto que foi dado, como foi dado, como foi trabalhado" (MADALENA, entrevista, terceiro dia de observação), uma vez que:

Os processos de estudos realizados dentro de uma instituição didática continuam vivos fora dela: a escola deve criar meios para que os alunos estudem e aprendam (mediante o ensino e outro tipo de atividade), mas também deve proporcionar-lhes instrumentos para que possam continuar estudando ao saírem da escola, após terminadas as aulas (CHEVALLARD et al., 2001, p. 58).

Quando Madalena se refere à necessidade do estudo, ela destaca que a falta dele prejudica principalmente na Matemática: "Eles não conseguem mais perceber que eles precisam estudar em casa. Então isso dificulta principalmente em Matemática, dificulta muito o nosso trabalho, nós temos muita dificuldade" (MADALENA, entrevista, terceiro dia de observação).

Diante dessas dificuldades, as professoras Madalena e Tereza procuram incentivar o hábito de estudo em seus alunos através de propostas de atividades, para que os mesmos levem para casa e apresentem a elas na aula seguinte. No primeiro dia de observação na sala da professora Madalena, ela nos disse:

Hoje eu vou trabalhar com atividades do livro, porque nós já trabalhamos na aula passada, então hoje nós vamos corrigir que é para nós podermos ver como eles entenderam, e depois vão ser passadas de novo outras atividades (MADALENA, entrevista, primeiro dia de observação).

Durante a nossa observação, nós percebemos que a professora Madalena estava verificando se os alunos fizeram as tarefas propostas na aula anterior, dessa forma, ela estava exigindo uma responsabilidade matemática de seus alunos. Além disso, ao perceber que sua estratégia não funcionou, ou seja, os alunos não resolveram as tarefas, a mesma disse que daria continuidade as atividades, destacando que é uma responsabilidade deles fazer as tarefas. 
Diante das falas analisadas dos professores em formação e dos formadores, nós identificamos que ocorreu uma transposição de tarefas, técnicas e tecnologias mobilizadas para o estudo de Matemática, ou seja, uma transposição de praxeologias. O processo de transposição foi desencadeado pela EAD e ocorreu de duas maneiras, uma transposição institucional e outra que nós podemos denominar como transposição intra-institucional, uma vez que ocorreu dentro de uma mesma instituição.

Essa transposição fica clara quando, no caso das professoras, elas mostram utilizar a mesma dinâmica que ocorria no curso de "IEM" e "Estágio", e por que não dizer em todas as outras disciplinas, uma vez que a prática é institucionalizada pelo curso. No caso da professora Tereza, ela destaca bem que, essa dinâmica, ela instituiu recentemente, quando em sua fala a mesma enfatiza a expressão "agora", ou seja, naquele momento.

Mas as práticas adotadas no curso, na modalidade à distância, foram adaptadas pelas professoras, pois a instituição em que agora elas estão situadas é uma escola municipal, com uma estrutura organizacional diferente da instituição em que as mesmas estudam. Nessa escola, elas sofrem influência da estrutura física do ambiente, da direção e supervisão, da cobrança dos pais, dos alunos e até de outros professores.

$\mathrm{Na}$ EAD, o aluno deve estudar as aulas do livro-texto antes dos encontros presenciais, ele não depende da explicação de um professor. No ensino presencial, o professor, de acordo com o contrato didático vigente, deve explicar aos alunos os conteúdos. Porém, as professoras Tereza e Madalena apresentam mais claramente que, para se aprender, não basta elas ensinarem, os alunos têm que estudar e com o estudo eles vão adquirindo mais responsabilidade. $\mathrm{O}$ processo de estudo se dá por meio de uma obra matemática. As duas professoras utilizam os livros didáticos, no caso de Madalena e Tereza, o livro didático é o adotado pela escola, mas a professora Tereza seleciona as atividades do livro e passa para eles copiarem no caderno.

À guisa de concluir sobre o processo de transposição de praxeologias didáticas da EAD para o ensino presencial, podemos identificar um entrelaçamento entre as falas dos formadores e das duas professoras em formação com nossas anotações no relatório de tutoria e diário de bordo. 
Nessa teia, nós podemos destacar a preocupação com o processo de estudo por meio de uma obra matemática, a formação de uma comunidade de estudos e a busca por uma responsabilidade matemática.

\section{Considerações finais}

No modelo de "Educação à Distância" (EAD), adotado no curso de Licenciatura em Matemática da UFPA, percebemos um currículo distinto do presencial, principalmente quanto à organização das disciplinas, às obras matemáticas a serem estudadas e à dinâmica de ação dos atores envolvidos. Essa dinâmica nos remeteu a reflexões sobre pressupostos da "Teoria Antropológica do Didático" (TAD), que se evidenciavam, de outro modo, se materializavam naquele processo, principalmente pelas práticas ali desenvolvidas, que se distinguiam das desenvolvidas no curso presencial de Licenciatura em Matemática.

Diante desse modelo de organizações didáticas do referido curso e sob a ótica da TAD identificamos, em nossas análises, um processo de mudanças de prática docente dos sujeitos investigados no sentido de uma transposição de praxeologias. Os processos de mudança, evidenciados em nossas análises, nos remetem a uma transposição de praxeologias didáticas. Essas transposições foram desencadeadas pela experiência dos sujeitos investigados no curso de Licenciatura em Matemática, na modalidade à distância como um todo.

Em nossa análise, identificamos que os processos de transposição de praxeologias, além de ocorrerem de uma instituição para outra (transposição institucional), eles ocorrem dentro de uma mesma instituição. Nesse sentido, houve um processo de transposição de praxeologias didáticas da modalidade de ensino à distância para a modalidade de ensino presencial.

No modelo de EAD, adotado pelo curso de Licenciatura em Matemática da UFPA, nós observamos que os atores envolvidos assumiam como postulado a minimização do ensino, concernente a participação de um professor em sala de aula e a necessidade de organizações matemáticas que privilegiassem a compreensão do aluno (professor em formação), sua autonomia e responsabilidade pela sua aprendizagem por meio do estudo.

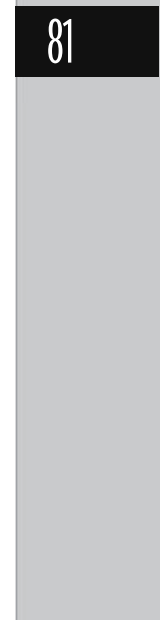


Nesse contexto, os formadores evidenciaram uma necessidade e preocupação em (re)construir organizações matemáticas que buscassem privilegiar fazeres construtivos dos formandos, assumindo estes como sujeitos engajados no processo de estudo, individualmente ou em grupos, sob a coordenação do tutor.

Os professores em formação, por sua vez, assumiram o processo de ensino, uma vez que, com a ausência de um professor de forma constante, eles tiveram que ensinar a si mesmos e ensinar os seus colegas. Esses professores eram "obrigados" a entrar em um processo de estudo, por meio da obra matemática, adquirindo assim uma crescente responsabilidade matemática.

Desse modo, as práticas instituídas nesse modelo de EAD propiciaram uma valorização da atividade matemática desses formandos, uma vez que suas tarefas realizadas foram institucionalizadas durante as tutorias presenciais, compartilhadas com a comunidade de estudos em que estavam inseridos. Os formandos eram "convocados" a ir ao quadro resolver os problemas, expor suas dúvidas e apresentar os resultados obtidos, além de fazerem a entrega das listas de atividades para o tutor. A formação da comunidade de estudos se tornou evidente, uma vez que estes sujeitos estavam envolvidos em torno de um conjunto de tarefas e compartilhavam as vitórias e os insucessos.

O tutor, por sua vez, responsável pelos interesses institucionais da $\mathrm{EAD}$, promovia o estímulo à autonomia, responsabilidade com a aprendizagem traduzida, principalmente, por atribuir ao formando a responsabilidade perante ele e seus colegas, nos momentos de tutoria, do domínio das técnicas e tecnologias do objeto de estudo. O resultado do seu trabalho, bem como, do processo de estudo dos formandos, era legitimado pelas avaliações externas, uma vez que estas eram elaboradas pelo coordenador de disciplina que não fazia parte diretamente da comunidade de estudos. Percebemos, nesse sentido, uma responsabilidade matemática mais evidente por parte do tutor.

Sob esse enfoque de valorização da obra matemática, do processo de estudo, das responsabilidades matemáticas dos alunos (professores 
em formação) e dos formadores (tutor e/ou coordenador de disciplina), o que podemos esperar da prática docente ou das praxeologias desenvolvidas por esses atores no ensino presencial, após vivenciarem a experiência ou serem (trans)formados, na modalidade de ensino à distância?

Nossa pesquisa revela que os sujeitos investigados - professores em formação e formadores - são (trans)formados por meio dessa experiência evidenciada em suas práticas no ensino presencial em que passou a ser valorizada, de forma mais explicita, a obra matemática, o processo de estudo, a responsabilidade matemática e as comunidades de estudo, dividindo com seus alunos a responsabilidade pelo processo de ensino e aprendizagem. Identificamos assim, à luz da TAD, uma transposição de praxeologias didáticas desencadeada pela EAD.

Percebemos que a transposição de praxeologias propiciou uma mudança de postura dos sujeitos investigados em suas salas de aula do ensino presencial. Eles fizeram mais que uma "adaptação" de praxeologias didáticas instituídas pelo curso para o ensino presencial, pois manifestaram em seus fazeres docentes uma maior autonomia sobre a utilização das (novas) praxeologias.

Os resultados obtidos em nossa pesquisa apontam possíveis contribuições do ensino a distância para o ensino presencial. No entanto, julgamos necessário buscar compreender, por exemplo, as relações entre os elementos presentes na $\mathrm{EAD}$, sob a luz da TAD, como a responsabilidade matemática de formadores, a obra matemática por eles elaborada, a comunidade de estudo, o estudo da obra e a responsabilidade matemática dos formandos, de modo a identificar em que condições tais relações podem contribuir para o processo de formação inicial e continuada de professores da matemática.

Essas questões, e outras relacionadas ao processo didático nessa modalidade de ensino, nos encaminham para pesquisas futuras sobre as relações entre ensino à distancia e formação inicial e continuada de professores de Matemática sob a luz da "Teoria Antropológica do Didático". 
ALONSO, K. M. A educação a distância e um programa institucional de formação de professores em exercício. In: PRETI, O. (Org.). Educação a Distância: construindo significados. $1^{\mathrm{a}}$ Ed. Brasília: Plano, 2000, v. 1, p. 229-244.

BARROS, D. M. V. Educação à distância e o universo de trabalho. Bauru: EDUC, 2003.

BOGDAN, R. C.; BIKLEN, S. K. Investigação qualitativa em educação: uma introdução à teoria e aos métodos. Trad. de Maria J. Álvares, Sara B. dos Santos e Telmo M. Baptista. Portugal: Porto Editora, 1994. (Coleção Ciências da Educação).

BOSCH, M.; GASCÓN, J. Las prácticas docentes del profesor de matemáticas. Documento de trabajo en periodo de elaboración (2001). Disponível em: http://www.ugr.es/ jgodino/siidm/almeria/Practicas_ docentes.PDF. Acesso em abril de 2008.

CHEVALLARD, Y. El análisis de las pácticas docentes en la teoria antropológica de lo didáctico. In: Recherches em Didactique des Mathématiques, v. 19, n. 2, 1999. p. 221-266.

CHEVALLARD, Y. et al. Estudar matemáticas, o elo perdido entre o ensino e a aprendizagem. Trad. Daisy Vaz Moares. Porto Alegre: Artes Médicas, 2001.

CHEVALLARD, Y. La transposición didáctia: del saber sábio al saber enseñado. $3^{\text {a }}$ Ed. $2^{\text {a }}$ reimp. Buenos Aires: Aique Grupo Editor, 2005.

LÜDKE, M.; ANDRÉ, M. E. D. A. Pesquisa em educação: abordagens qualitativas. São Paulo: EPU, 1986. (Temas básicos em educação e ensino).

PAIS, L. C. Didática da Matemática: uma análise da influência francesa. Belo Horizonte: Autêntica, 2001. (Coleção Tendências).

PAIS, L. C. Transposição Didática. In: MACHADO, S. D. A. et al. Educação Matemática: uma introdução. São Paulo: EDUC, 2002, p. 13-42. (Série Trilhas). 